\title{
O som ressoante dos tambores
}

\author{
Flávia Cristina Bandeca Biazetto ${ }^{1}$
}

RESUMO: O poeta moçambicano José Craveirinha, influenciado pelo movimento da Negritude, aborda em seus versos questões sobre as contradições no Regime Colonial, valorizando a cultura, a luta e a História de seu povo. Este trabalho aponta alguns aspectos de seu projeto literário, tendo por base o poema Quero ser Tambor, publicado no livro Karingana ua Karingana (1982). A proposta é analisar o poema, destacando os elementos da cultura africana e os recursos literários utilizados pelo poeta para enfatizar a valorização de uma moçambicanidade.

ABSTRACT: José Craveirinha was a poet from Mozambique who broached the Colonialism's contradictions under the influence of Negritude. The Craverinhas's verses value the culture, the struggle and History of his country. This research intends to analyse the literature project of Craverinha, based on the poem Quero ser tambor, published in Karingana ua Karingana (1982). The proposal of this analysis is to emphasize African culture elements and the literary mean which were used by Craveirinha in order to value the aspects of the Mozambican culture.

PALAVRAS-CHAVE: Poesia, Craveirinha, Negritude, literatura moçambicana KEYWORDS: Poetry, Craveirinha, Negritude, Mozambican Literature

O presente trabalho tem por objetivo apontar características do projeto literário do poeta moçambicano José Craveirinha, tendo por base o poema "Quero ser Tambor", publicado em Karingana ua Karingana (1982). Sobre este livro, Rita Chaves explica:

Indo à tradição mais antiga, ele se equipa para fundar as bases de uma poesia que se faz moderna na confrontação que propõe. Sua modernidade se reafirma nas recusas das linhas de uma tradição que não aceita como sua. $O$ resgate das referências africanas torna-se uma espécie de compromisso nos textos em que se diversificam as formas de apelo a uma origem que a

\footnotetext{
1 Mestranda em Estudos Comparados de literaturas de Língua Portuguesa, FFLCHUSP. Pesquisa: Análise comparativa entre as crônicas de Mia Couto e Antônio Lobo Antunes.

E-mail: fla_bandeca@yahoo.com.br
} 
dinâmica colonial de certo modo pretendia diluir. (CHAVES, 2005, p. 195)

Tendo em vista o fragmento acima transcrito, é possível interpretar que a obra Karingana ua Karingana destaca a diversidade cultural de Moçambique e simultaneamente evidencia mecanismos de opressão do regime colonial, por exemplo, o de desvalorização da cultura local como forma de legitimar a cultura do colonizador.

Para o desenvolvimento de tal estudo recuperaremos alguns aspectos da biografia do poeta estudado. É válido ressaltar que o biografismo aqui é apropriado não de forma reducionista, tentando forjar uma relação entre obra e vida do autor, mas sim é cunhado na questão da experiência vivida pelo poeta.

Em meio ao Regime Colonial, com toda sua violência e exclusão, os versos de Craveirinha surgem, dando voz aos excluídos e marginalizados pelo colonialismo. Diante de um sistema totalmente segregador, no qual brancos tinham privilégios e negros sofriam um processo quase de animalização e tinham suas culturas dizimadas pelos os colonizadores, Craveirinha gozava de uma certa vantagem de vivenciar tanto a cultura dos brancos, como a dos negros - devido à sua condição mestiça de filho de português com uma africana. Essa sua experiência de trânsito entre as culturas da sociedade moçambicana foi materializada na forma como o poeta representou a diversidade cultural moçambicana. Sua poesia reflete a coexistência de aspectos contrários - intensificados pelo Regime Colonial -, denunciando os pontos de tensão e convivência pacífica entre os mesmos. Isso é recriado em sua obra tanto por meio das temáticas e imagens, que remetem à exploração e à exclusão social, quanto através da linguagem com neologismos lusoronga. Como foi dito anteriormente, Craveirinha era de origem mestiça e, como muitos africanos, teve uma criação bilíngüe, o que o permitiu dominar tanto a língua portuguesa, quanto a ronga.

Ao colocar no centro da temática de sua produção literária aspectos da história e da cultura moçambicana, Craveirinha - assim como outros poetas de sua geração - cria um espaço em que é possível 
discutir e analisar o momento histórico. Esta produção literária, chamada de nacional, tem como signo a reivindicação de uma nacionalidade roubada pelo sistema colonial. Sobre esta corrente literária podemos citar Rita Chaves:

Para muitos deles tratava-se de fundar um projeto novo que assegurasse ao homem da terra um papel primordial, retirandolhe a carga exotizante com que o discurso colonial o apresentaria. A idéia de ruptura parecia-lhes, portanto, fundamental para a emergência de uma palavra nova que correspondesse ao sentido da nacionalidade que se começava a vislumbrar. (CHAVES, 2005, p. 290)

Diferentemente, a geração literária precedente focava em seus textos o colono e sua aventura em desbravar as terras africanas. Rita Chaves nos chama atenção para o fato de que, não raro, os heróis da literatura colonial tinham como recompensa o retorno a Portugal. Esta estudiosa das Literaturas Africanas de Língua Portuguesa ainda esclarece que, nesse período, tanto a natureza local quanto os negros são reificados pela literatura, tornado-se apenas elementos da paisagem exótica e rude que compunha o cenário africano.

A reivindicação de uma nacionalidade pelos poetas nacionalistas é resultado de um momento histórico que se inicia na década de 30 com o Ato Colonial. Esta medida política tinha como objetivo o domínio total das colônias portuguesas em África. Como instrumento para atingir tais metas, o governo português tenta difundir a imagem de Portugal como uma província ultramarina e a idéia de uma nação multicontinental, igualitária e fraterna.

Outra prática recorrente do sistema colonial português utilizada para controlar as colônias em África era o estatuto do assimilado, que garantia aos colonizados que os possuía certos privilégios como direito ao voto, ao deslocamento dentro do território nacional e à igualdade de salários entre colonizados e colonizadores. Luís Abel Cezerrilo analisa em sua tese de doutorado o processo de assimilação: 
A política de assimilação, que se revelou apenas geradora de um grupo de intelectuais e funcionários, retira dos mesmos indivíduos qualquer possibilidade de se tornarem sujeitos, para manterem-nos como dóceis instrumentos ao serviço de um regime com interesses e aspirações contrárias às dos seus povos. (CEZERILLO, 2004, p.68)

Nesse período de dominação e contradições da história de Moçambique, surgem organizações políticas que buscavam incitar a reflexão sobre a origem moçambicana e os problemas das condições de trabalho no sistema colonial. Estas associações eram formadas basicamente por mestiços e negros com um nível mais eleva de instrução e que ansiavam por um país mais igualitário. Craverinha e outros poetas de sua geração como Rui Guerra, Rui Knopfli e Noémia de Sousa mantinham um grupo que se reunia periodicamente com o intuito de discutir a situação colonial. Em entrevista cedida à professora Dr $^{\mathrm{a}}$ Rita Chaves, Craverinha definiu esta associação de poetas que discutiam temas políticos da seguinte forma:

Era uma fase de grande inquietação. Estávamos ligados pela vontade de mudar. Tínhamos consciência da injustiça que dividia essa sociedade. As atividades culturais promovidas pela Associação africana.Ela foi fundada por negros e por mestiços.Era freqüentada pelos Albasinis, pelo Karel Pott, por toda essa gente que tinha um nível mais elevado de instrução. A associação era um lugar onde se discutia o que era ser africano, o que era ser moçambicano. (CHAVES, 2005, p. 238)

A vivência de Craveirinha tanto em meio aos colonizadores quanto aos negros marginalizados nos bairros de Caniço se materializa em sua escrita, dando ao seu poetar uma espécie de voz da coletividade. $\mathrm{O}$ poeta registra em sua obra um desencantamento e um desejo de superação dos constrangimentos do presente, criando assim, a imagem de um futuro melhor, que era o lampejo de esperança dos excluídos pelo colonialismo.

Diante dessa expressão utópica nos versos de Craveirinha, podemos traçar um paralelo entre sua lírica e o pensamento de Adorno. 
Tal aproximação é possível, mesmo tendo a teoria adorniana reflexões sobre outro período e outro contexto espacial geográfico:

\begin{abstract}
Seu distanciamento da mera existência torna-se medida do que há nesta de falso e de ruim. Em protesto contra ela, o poema enuncia o sonho de um mundo em que essa situação seria diferente. A idiossincrasia do espírito lírico contra a prepotência das coisas é uma forma de reação à coisificação do mundo, à dominação da mercadoria sobre os homens (ADORNO, 2003, p. 69).
\end{abstract}

Ao proferir tais palavras, é provável que Adorno tivesse em mente o processo de massificação da sociedade - escopo de grande parte de seus estudos-, entretanto, creio ser possível associarmos a coisificação, mencionada no fragmento acima, ao processo semelhante do sistema colonial. No colonialismo, os colonizados eram vistos como instrumentos de trabalho, sendo explorados e tendo suas culturas e necessidades ignoradas pelos colonizadores. Esses últimos usam um discurso, em que falseavam uma superioridade civilizadora e propagavam uma incumbência de espalhar seus valores de "civilização", exaltando assim sua cultura e depreciando a do colonizado. Dentro deste contexto, os colonizados eram freqüentemente associados a "bárbaros", "ignorantes", "povo sem cultura e sem história”. Essa desvalorização e desumanização dos africanos eram feitas como uma forma de justificar a dinâmica colonialista imposta em África.

À luz do pensamento de Adorno, podemos entender a poesia nacionalista de Craveirinha e seus contemporâneos como uma forma de denúncia de uma existência forjada e reificada pelos colonizadores. Dentro desse contexto colonial, a lírica se torna não só um instrumento de denúncia e reivindicação, mas também um elemento conscientizador e propagador dos sonhos e utopias de toda uma sociedade.

O poema escolhido, para aqui ser analisado, tem por eixo temático o desejo do eu-lírico de ser tambor; ou seja, de assumir sua moçambicanidade. A busca por uma identidade nacional era reivindicação recorrente nas colônias africanas, durante o século XX. Influenciados pelas idéias pan-africanistas e da Negritude, muitos 
intelectuais africanos buscavam retratar os negros no centro de suas obras. A visão de Craveirinha sobre o colonialismo se aproximava da de Césaire e da de Fanon, ou seja, encarava o racismo como centro da engrenagem colonial. Sob este ângulo, Craveirinha recupera manifestações culturais populares moçambicanas em uma tentativa de denunciar as estratégias do colonizador de cooptar os colonizados.

Em "Quero ser tambor", há logo no início a exteriorização do anseio da voz central do poema:

Tambor está velho de gritar
Oh velho Deus dos homens
deixa-me ser tambor
corpo e alma só tambor
só tambor gritando na noite quente dos trópicos.

Tendo estes versos em vista, nota-se que o eu-lírico reivindica o seu direito de ser moçambicano, por meio da imagem do tambor. Este objeto, ao ser evocado, possibilita duas leituras não excludentes. A primeira remete ao tambor como um instrumento utilizado em guerras; tendo isso em vista, é possível interpretar uma convocação do poeta para uma guerra contra a exploração colonial. Já a segunda evoca as batidas do tambor em rituais de iniciação, nos quais os indivíduos são preparados para uma nova etapa da vida. Assim, há a possibilidade de se inferir que os versos da primeira estrofe expressam o desejo de superar a condição colonial, na qual valores culturais moçambicanos são desvalorizados e apontam simultaneamente para a utopia de atingir uma nova etapa, na qual haja uma valorização da condição humana do povo moçambicano.

As duas interpretações aqui apontadas convergem para a questão da comunicação, isto é, o tambor como instrumento de anunciação de transformação - representados seja por tempos de guerra, seja por ritos de passagem. Nesse sentido, é possivel pensar que o poema anuncia uma mudança futura. Ao valer-se da imagem do tambor nesses versos, Craveirinha reforça a intenção de estabelecer um diálogo entre o eu- 
lírico e seus leitores, quiçá com o intuito de denunciar a situação representada.

Ao dizer que deseja ser "corpo e alma só tambor", o eu-lírico mostra uma consciência do processo de desumanização que o sistema colonial impunha e a vontade de se resgatar a humanidade roubada pelo regime. Para explicar esta idéia, tem-se em mente a própria constituição do homem africano que, segundo Fábio Leite (1995/1996), é formado de corpo, espiritualidade e imortalidade. Ao se pensar em um tambor constituído de corpo e alma da mesma essência, é possível fazer uma leitura, na qual se entendam dois dos elementos constituintes do homem na concepção africana tradicional. Confrontando os versos "tambor está velho de gritar" e "só tambor gritando na noite quente dos trópicos” está presente a noção de continuidade de um grito, que já é velho, mas que quer se renovar. Assim, nota-se o terceiro elemento que Leite aponta como formador do homem: a imortalidade, indissociável da idéia de ancestralidade.

Após a afirmação da vontade de ser tambor e de exteriorizar um grito, que em certa medida, não se materializa, há a descrição de elementos que o eu-lírico não ambiciona se transformar:

Nem flor nascida no mato do desespero Nem rio correndo para o mar do desespero Nem zagaia temperada no lume vivo do desespero Nem mesmo poesia forjada na dor rubra do desespero.

Nem nada!

Estes versos são constituídos por sucessivas negações, que serão sintetizadas na estrofe seguinte, por meio de seu único verso: "Nem nada!". O eu-lírico nega a vontade de ser flor, rio e poesia, ou seja, recusa a aparente estabilidade do sistema colonial. Implicitamente a esta renúncia, ele denuncia as injustiças sociais, por meio da repetição da locução “do desespero", reiterando que tudo o que é negado faz parte de um contexto de angústia, aflição e sofrimento, causado pela exploração colonial. 
Como já foi dito anteriormente, ser tambor significa resgatar sua condição de homem, sobretudo sua moçambicanidade. O poema é construído com uma certa musicalidade que lembra a do tambor, sendo ritmado nas cadências e sons que simulam este instrumento e fazem com que a voz central do poema ressoasse em um espaço. Ser tambor permite a manifestação do sujeito que o evoca, tornando um meio de denúncia e de clamor pela identidade nacional. Assim, a evocação de valores nacionais, por meio da imagem do tambor, indica uma ligação deste poema com o contexto internacional da Negritude.

Munanga afirma que os objetivos desse movimento eram: "buscar o desafio cultural do mundo negro (a identidade negra africana), protestar contra a ordem colonial, lutar pela emancipação de seus povos" (MUNANGA, 1988, p. 40). Esse autor explica, ainda, que poetas, romancistas e intelectuais buscavam restituir o orgulho de ser negro e do passado, em uma tentativa de afirmar os valores de suas culturas, que estavam sendo sufocadas pela assimilação dos valores do colonizador.

À luz desta definição de Negritude, pode-se arriscar dizer que a presença deste movimento na poesia de Craveirinha tinha a função de denunciar o sistema colonial e suas formas de sustentação. Sob este aspecto, o racismo - retratado como uma das facetas do abuso colonial - e a cultura popular moçambicana são tematizados como uma estratégia de desmontar o discurso colonialista de desqualificação do colonizado.

Ao se deter nos verbos da segunda estrofe: nascer, correr, temperar e forjar, nota-se que ações tão naturais da vida vão convergir para o verbo forjar, o que permite interpretar que o sistema colonial inventava uma realidade que não era a moçambicana e é daí que surge a reivindicação de ser tambor, isto é, africano.

O ritmo do tambor, sugerido por meio dos versos clamados, reforça a identidade moçambicana e funde o batuque, representado pela repetição das palavras, com a voz do eu-lírico, provando que a 
moçambicanidade está inerente ao eu-lírico, mesmo que as condições históricas tentem escamoteá-la.

Craverinha não exalta só a condição do homem africano, mas também da natureza local:

Só tambor velho de gritar na lua cheia da minha terra

Só tambor de pele curtida ao sol da minha terra

Só tambor cavado nos troncos duros da minha terra.

Na esteira da valorização de elementos moçambicanos, percebe-se nesses versos a consagração da terra e alguns de seus elementos: lua cheia, pele - metonímia do homem - sol e troncos duros. Há uma sugestão de uma fusão entre homem e natureza, por meio da justaposição de imagens que nos remetem ora aos homens - o ato de gritar, a pele —, ora à natureza - sol, lua e troncos. Essas imagens levam a um processo de enrijecimento das pessoas, por meio do último verso da estrofe citada. Quando se examina os versos reproduzidos acima, nota-se que o poeta restringe, por meio do advérbio "só", tal fusão, permitindo interpretar que tal processo não atingia a todos e sim somente uma parcela da população.

Eu

Só tambor rebentando o silêncio amargo da Mafalala

Só tambor velho de sentar no batuque da minha terra

Só tambor perdido na escuridão da noite perdida.

À luz desta estrofe, nota-se que o eu-lírico destaca a sua individualidade, que é expressada pelo pronome "eu". Ao espacializar os versos na Mafalala, que é um bairro periférico de Lourenço Marques, o poeta faz referência a sua vivência, visto que foi neste espaço que ele viveu muito tempo. Quando se toma por base a expressão "silêncio amargo da Mafalala”, pode-se inferir que a qualificação amarga faz referência direta às condições precárias e às humilhações, em que os habitantes da Mafalala vivem. O som do batuque do tambor mistura-se com o desespero do eu-poético que se encontra "perdido na escuridão da noite perdida”. Há a sugestão da imagem de um ambiente silencioso 
e solitário, mas no qual o som dos tambores ressoa, remetendo-se a uma moçambicanidade latente, em meio às imposições do Império luso em África.

$\mathrm{Na}$ última estrofe, tem-se uma repetição das idéias aqui sugeridas: o desejo de resgatar a moçambicanidade e de denunciar as atrocidades do regime colonial:

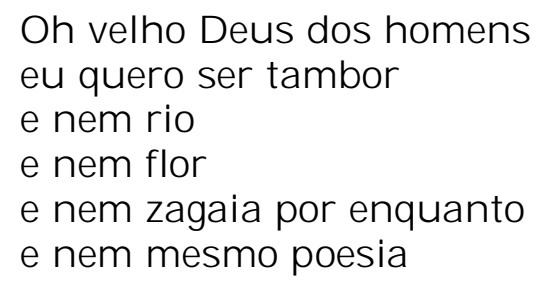

Apesar da temática destes versos ser repetida ao longo do poema, notamos que aqui no quinto verso o eu-lírico faz uma restrição temporal, pois ele expressa não querer ser uma lança "por enquanto". Ainda analisando este verso, nota-se que o eu-lírico tenta postergar uma luta, mas esta já existe em um âmbito ideológico em sua poesia, que também é negada no fragmento reproduzido acima. Podemos entender tal negação como uma extensão da não-aceitação da realidade, que nos remetem estes versos.

A vontade de se resgatar a moçambicanidade roubada pelo sistema colonial se mistura ao tempo e se concretiza em uma festa, na qual o som do batuque predomina:

Só tambor ecoando como a canção da força e da vida

Só tambor noite e dia

Dia e noite só tambor

Até a consumação da grande festa do batuque!

Esses versos apontam para uma utopia, aqui utilizada de acordo com a teoria de Ernst Bloch; para ele, a utopia não constitui um topos idealizado ou projetado, como era para Platão e para os filósofos do Renascimento (Thomas Morus, Campanella, Bacon); utopia é, em primeiro lugar, um topos da atividade humana orientada para um 
futuro, um topos da consciência antecipadora e a força ativa dos sonhos diurnos.

Rita Chaves explica que:

\begin{abstract}
Vivendo experiências de incomunicabilidade, o poeta vai com sua poesia, incursionar pelos trilhos da pluralidade, buscando a utopia de um projeto calcado na aceitação das diferenças, contrariando, assim, a perspectiva de que a unidade resida na pureza. Em seus versos, a defesa do enraizamento na matriz cultural africana, com seus ritmos, seus rituais, suas tradições, todo seu patrimônio, coexiste com a serena aceitação do legado da cultura lusitana. (CHAVES, 2003, p. 218)
\end{abstract}

Por fim, nota-se que a realização de se transformar em tambor não depende do eu-lírico; e sim de uma força externa a ele. Isso fica evidente na última estrofe, pois o poeta fala:

Oh velho Deus dos homens

eu quero ser tambor

Oh velho Deus dos homens

Deixa-me ser tambor

Só tambor!

Ao pedir permissão a Deus para ser tambor, fica claro que algo o impede de sê-lo, havendo assim a necessidade de algo fora de sua individualidade agir para que isso se suceda. Por meio dos versos citados, percebe-se que o eu-lírico não está livre, e sim em um estado de submissão, pois ele pede permissão para se transformar em tambor, mostrando assim a consciência do funcionamento do regime colonial.

Apesar de todos os limites do colonialismo, Craveirinha registra em seus versos os valores culturais moçambicanos e o sonho da libertação da opressão colonial, dando à sua voz e aos seus versos o tom forte e ressoante dos tambores africanos, mostrando assim que a liberdade não era um sonho individual, mas de toda uma coletividade que não podia se expressar. 


\section{Referências bibliográficas}

ADORNO, Theodor. Notas de Literatura I. São Paulo: Duas Cidades, Ed.34, 2003.

CEZERILLO, Luís Abel. Obra poética de José Craveirinha e Eduardo White: utopia e liberdade no horizonte do possível. Tese/USP: 2004.

CHAVES, Rita. Angola e Moçambique nos anos 60: a periferia no centro do território poético. In Via atlântica, publicação da Área de Estudos Comparados de Literaturas de Língua Portuguesa da USP, n. ${ }^{\circ}$ 5, 2003, p. 205 a 221.

- Frantz Fanon colonialismo, violência e identidade cultural. In Margens da cultura. São Paulo: Boitempo, s/d.

. José Craveirinha, da Mafalala, de Moçambique, do mundo. In Via atlântica, publicação da Área de Estudos Comparados de Literaturas de Língua Portuguesa da USP, n. ${ }^{\circ}$ 3, 1999, p. 140 a 168.

Angola e Moçambique. Experiência colonial e territórios literários. São Paulo: Ateliê, 2005.

CRAVEIRINHA, José. Obra completa. Maputo: Imprensa Universitária, 2000.

FANON, Franz. Os condenados da terra. Rio de Janeiro: Civilização Brasileira, 1979.

LEITE, Ana Mafalda. A fraternidade das palavras. In Via atlântica, publicação da Área de Estudos Comparados de Literaturas de Língua Portuguesa da USP, n. ${ }^{\circ}$ 5, 2002 p. 21 a 28.

LEITE, Fábio. Valores civilizatórios em sociedade negro-africanas. In África: Revista do Centro de estudos africanos. USP, 18-19 (1) 103-118.19951996.

MENDONÇA, Fátima. O conceito de nação em José Craveirinha, Rui Knopli e Sérgio Vieira. In Via atlântica, publicação da Área de Estudos Comparados de Literaturas de Língua Portuguesa da USP, n. ${ }^{\circ}$ 5, 2002 p. 53 a 66.

MUNANGA, Kabenguele. Negritude. Usos e destino. 2. ${ }^{\mathrm{a}}$ ed. São Paulo: Ática, 1988.

MÜNSTER, Arno. Ernst Bloch - Filosofia da Práxis e Utopia Concreta. São Paulo: Ed. Unesp, 1991.

NOA, Francisco. José Craveirinha: para além da utopia. In Via atlântica, publicação da Área de Estudos Comparados de Literaturas de Língua Portuguesa da USP, n. ${ }^{\circ}$ 5, 2002, p. 68 a 76. 